\title{
Rain-Gauge Network Evaluations Using Spatiotemporal Correlation Structure for Semi-Mountainous Regions
}

\author{
Yong Jung ${ }^{1,3}$, Hyunglok Kim ${ }^{1}$, Jongjin Baik ${ }^{1,2}$, and Minha Choi ${ }^{2, *}$ \\ ${ }^{I}$ Department of Civil and Environmental Engineering, Hanyang University, Seoul, Republic of Korea \\ ${ }^{2}$ Water Resources and Remote Sensing Laboratory, School of Civil, Architectural, and Environmental Engineering, \\ Sungkyunkwan University, Suwon, Republic of Korea \\ ${ }^{3}$ Water Resources Research Division, Korea Institute of Construction Technology, Goyang-si, Republic of Korea
}

Received 13 February 2013, accepted 31 October 2013

\begin{abstract}
A reliable network of rain gauges is a crucial component of rainfall estimation in a watershed. To provide a better evaluation method for rain-gauge networks, a new evaluation method using average inter-gauge correlation coefficients (averaged CC) for estimating an effective radius for each rain gauge was developed. In this study, averaged CCs were obtained from the values of inter-gauge correlation coefficients after choosing a minimum number of rainfall data sets as a threshold. The Nam River Basin $\left(2400 \mathrm{~km}^{2}\right)$ and its 24 rain gauges were selected with 8 years $(2003-2010)$ rainfall data to validate a new evaluation method. In the spatial correlation coefficient fitting process for generating correlation distances, averaged CCs increased fitness accuracy (maximum 37\%) in terms of coefficient of determination $\left(R^{2}\right)$ compared with a commonly used method (the last value of the inter-gauge correlation coefficient as the number of data sets is increased: last CC). In the evaluation of effective radii for 8 years, the robustness of the averaged CCs was supported by lower standard deviations for all rain gauges. For the optimum coverage of rainfall estimation in terms of effective radius, the Nam River Basin requires 20 rain gauges. Investigation of altitude effects presented that the effective radii were minimally influenced by the altitude of rain-gauge locations for this area.
\end{abstract}

Key words: Rain-gauge distribution, Correlation length, Effective area, Altitude effects

Citation: Jung, Y., H. Kim, J. Baik, and M. Choi, 2014: Rain-gauge network evaluations using spatiotemporal correlation structure for semi-mountainous regions. Terr. Atmos. Ocean. Sci., 25, 267-278, doi: 10.3319/TAO.2013.10.31.01(Hy)

\section{INTRODUCTION}

Precipitation estimation is essential for hydrologic modeling of physical phenomena to mitigate flood hazards. Precipitation uncertainty due to spatiotemporal distribution strongly influences flood forecasting and warnings associated with incorrect flow simulations (Berndtsson and Niemczynowicz 1988; Morin et al. 1995; Johnson et al. 1999; Tsintikidis et al. 2002; Younger et al. 2009; Arnaud et al. 2011). In particular, mountainous regions require more reliable precipitation estimation because the interaction between mountainous terrain and the atmosphere increases the variability of precipitation patterns and the precipitation amounts related to the mesoscale precipitation process (Krajewski and Georgakakos 1994; Wheater et al. 2000). To

\footnotetext{
* Corresponding author

E-mail:mhchoi@skku.edu
}

account for the temporal and spatial variability of precipitation, there are several advanced approaches such as weather radar, satellite rainfall estimation algorithms, and numerical weather models. However, most cases require a validation and calibration process with measured rainfall data from existing rain gauges to reduce the measurement errors (Frei and Schär 1998; Pardo-Igúzquiza 1998; Adler et al. 2001; McCollum et al. 2002; Berne et al. 2004; Xie et al. 2007; Chen et al. 2008; Piman and Babel 2013). In addition, some studies combined the remotely sensed data with rain-gauge measurements for better estimates of point or areal rainfalls (Krajewski 1987; North et al. 1991). Therefore, reliable rainfall measurements at rain gauges are still necessary to elucidate the spatiotemporal variability of precipitation.

To improve the accuracy of rainfall estimation for watersheds using rain gauges, a network of rain gauges has been studied using various evaluation methods. Entropy of 
rainfall observations based on variable uncertainties was applied for the assessment of rain-gauge network evaluation (Al-Zahrani and Husain 1998; Chen and et al. 2008). Rationalization based on multivariate analyses was used to eliminate rain-gauge redundancy for the optimum rain-gauge network (Burn and Goulter 1991). Geostatistical frameworks have been utilized for optimal distribution of the rain-gauge monitoring network, because these can produce unbiased estimators with minimum error variance (Tsintikidis et al. 2002; Barca et al. 2008; Chen et al. 2008; Cheng et al. 2008; Chebbi et al. 2011). In the geostatistical applications, Bastin et al. (1984) and Kassim and Kottegoda (1991) used the iterative manner to select rain-gauge locations associated with minimum kriging variance. Pardo-Igúzquiza (1998) applied a geostatistical variance-reduction method with simulated annealing as an optimization tool for an optimal network design to obtain areal averages of rainfall events. Inter-gauge correlation is also useful in rain-gauge network design to find the optimal spacing of rain gauges. In the application of inter-gauge correlation, Ciach and Krajewski (2006) analyzed the spatial correlation structure in small-scale rainfall using a dense cluster of rain gauges. They evaluated the effect of time-scale range, inter-storm variability, and rainfall intensity. Furthermore, to characterize the spatiotemporal variability of the rainfall intensity, Ha and Yoo (2007) used the inter-station correlation coefficient of the rainfall intensity derived from the mixed bivariate rainfall distribution. Based on the use of inter-gauge correlation, the purpose of this study is to assess a rain-gauge distribution to increase capability and efficiency in rainfall measurements. The newly developed average inter-gauge correlation coefficient (averaged CC) was applied to obtain an effective radius for each rain gauge with the rain-gauge boundary for its effective area of precipitation measurement. Applications of the averaged CCs are substantially different from those of previous studies. A number of previous studies (Ciach and Krajewski 2006; Yoo and Ha 2007) adopted the last CC values using the total number of rainfall data sets to generate the spatial correlation coefficient diagram. The measured rainfall amount at each rain gauge was used to redistribute pre-existing rain gauges in a semi-mountainous region to enhance the resolution of spatiotemporal changes of precipitation. While estimating effective radii, a comparison between averaged $\mathrm{CC}$ and last $\mathrm{CC}$ applications presented the improved representation of an effective radius for each rain gauge. In addition, the altitude effects of pre-existing rain gauges in a mountainous region were evaluated.

The remainder of this paper is organized into the following sections: the description of the study area (i.e., the Nam River Basin) and the rainfall data sets; the major functions for the evaluations of rain-gauge distributions; the results and discussion of rain-gauge evaluations along with the altitude effects on rain-gauge measurements; and finally, the conclusions.

\section{STUDY REGION AND DATA SETS}

Figure 1 presents the study region, the Nam River Basin $\left(2400 \mathrm{~km}^{2}\right)$, located in the southern part of the Korean Peninsula. The 24 rainfall gauges within this river basin were evaluated for the correlation of rain gauges, the spatial correlation, and the individual radii of effective areas. For the evaluation of altitude effects based on rain-gauge locations, there are two separate classes of rain gauges: higher altitude (upper case letters) and lower altitude (lower case letters). For evaluation of data sets, hourly rainfall measurements from June to September 2003 - 2010 were obtained from the Water Management Information System (WAMIS) through Automated Weather Stations (AWS) in Korea and used to generate the effective radius of each rain gauge (http://www.wamis.go.kr/ eng/main.aspx/). With regard to the rainfall conditions at the two types of rain gauge, three observed rainfall conditions (cases A, B, and C) were defined. In case A, both rain gauges observed positive rainfall for their locations $(X>0$ and $Y>0)$. In case $\mathrm{B}$, only one rain gauge obtained positive rainfall $(X>0$ or $Y>0)$. In case $\mathrm{C}$, both rain gauges are positive but one or both may be zero $(X \geq 0$ and $Y \geq 0)$. For this study, only case A, the most important for flood control, was considered for evaluating the inter-gauge correlation (Yoo and Ha 2007). Some studies summed rainfall data over three or four years to generate the inter-gauge correlation since better inter-gauge correlation depends on more observed rainfall records with an assumption of homogenous rainfall. However, the summed rainfall data for three or four years is not realistic for the Korean Peninsula because this region has at most nine or ten days of consecutive rainfall events. Therefore, 250 hours for one year were chosen as the maximum number of hourly rainfall measurements to estimate the inter-gauge correlation coefficient for case $\mathrm{A}(X>0$ and $Y>0)$.

\section{METHODOLOGY}

To evaluate the rain-gauge network, the procedure shown in Fig. 2 was followed. The inter-gauge correlation coefficient was firstly applied to measure the interdependence of the rainfall intensity between two rain-gauge locations $(X$ and $Y$ ). Unlike the co-variance or the semi-variogram, the inter-gauge correlation coefficient is a normalized function that is not affected by the sample average-rainfall intensities (Krajewski et al. 2003). Each rain gauge has inter-gauge correlation coefficients with other rain gauges at various distances. For this study, 24 rain gauges were evaluated, providing 23 inter-gauge correlation coefficients for each rain gauge. If more rainfall data sets belonging to case A $(X>0$ and $Y>0)$ were available, more stable inter-gauge correlation coefficients could be obtained. However, the total number of rainfall data sets was accumulated within the specified duration for the evaluation. The equation for the inter-gauge correlation coefficient $\left(\rho_{X Y}\right)$ is: 

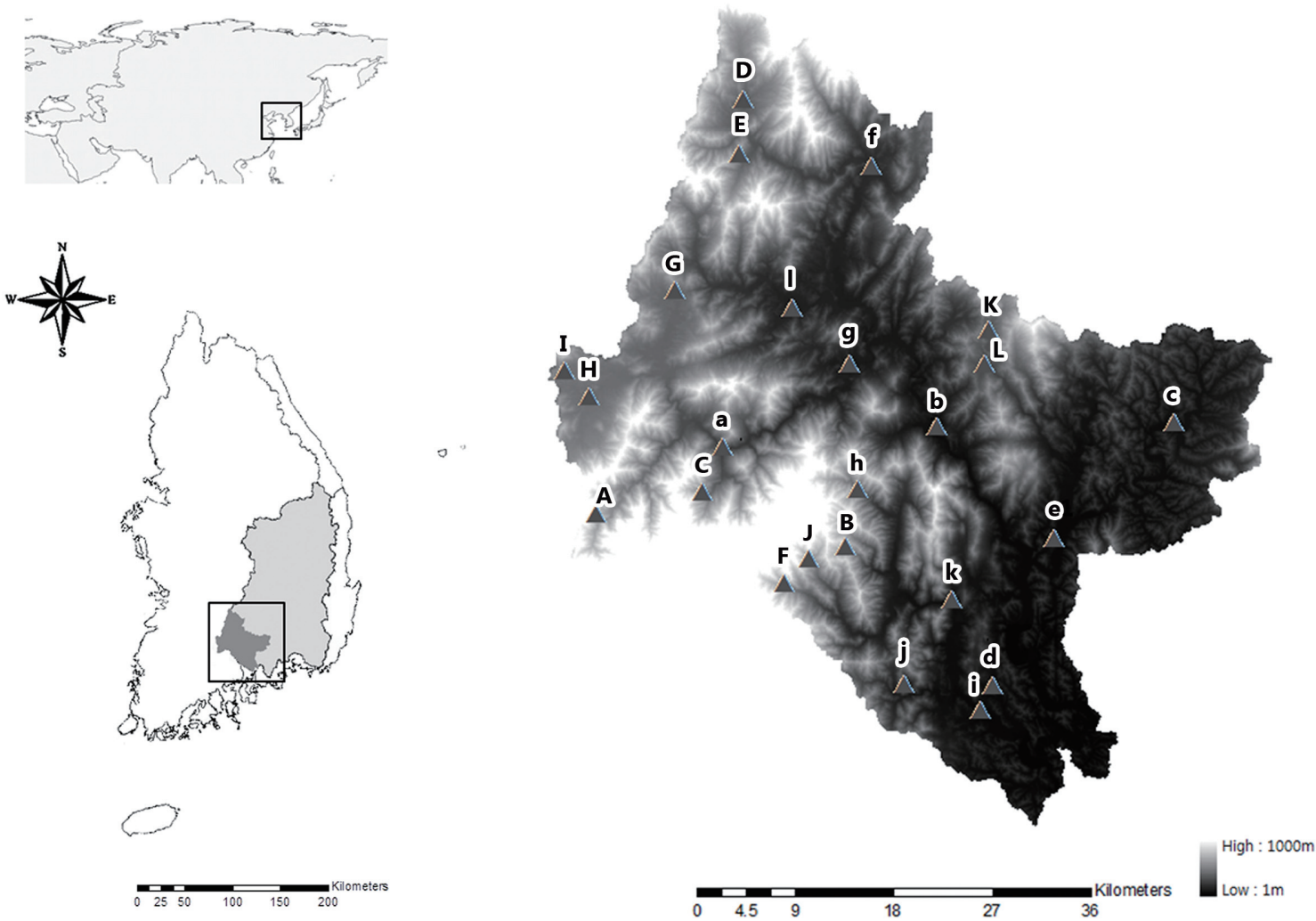

Fig. 1. The Nam River Basin, located in the southern part of South Korea, in Digital Elevation Model (DEM) format. The letters in the DEM indicate the locations of rain gauges: lower- and uppercase letters represent lower and higher altitude rain gauges, respectively.

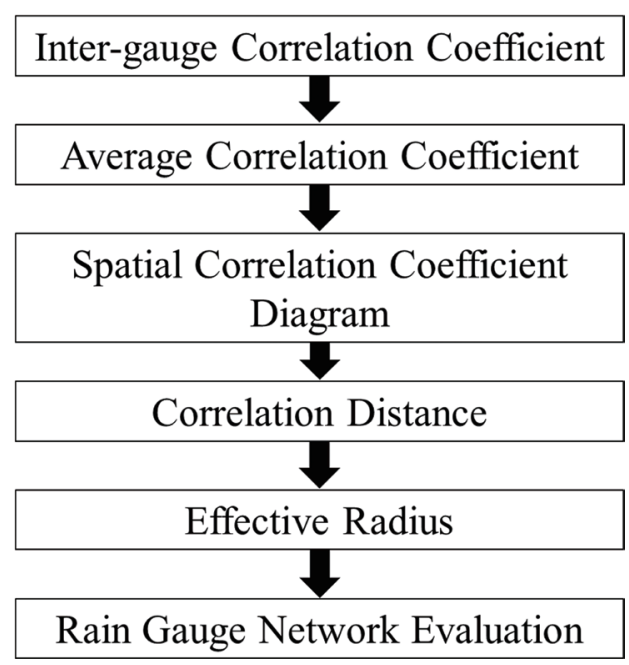

Fig. 2. Procedure for the assessment of a rain-gauge network.

$$
\rho_{X Y}=\frac{\operatorname{Cov}(X, Y)}{[\operatorname{Var}(X) \operatorname{Var}(Y)]^{0.5}}
$$

where $\operatorname{Cov}(X, Y)$ : Covariance of rain gauges at $X$ and $Y$. $\operatorname{Var}(X), \operatorname{Var}(Y)$ : Variances of rainfall at $X$ and $Y$, respectively.

Based on the inter-gauge correlation coefficients, an average inter-gauge correlation coefficient [averaged CC, $\left.\rho_{\text {ave }}(X Y)\right]$ for each distance was developed with the threshold applications on the number of rainfall data. The threshold is an optimum number of rainfall data starting with the steady-state correlation coefficient when rainfall data were added to measure the inter-gauge correlation coefficient as shown in Fig. 3. If the distance between rain gauges is small enough, a steady-state of correlation coefficient will be reached with a small number of rainfall data to define the relation between any two rain gauges. In contrast, if the distance between rain gauges is large, the steady-state of correlation coefficient will be reached only after a large amount of rainfall data has been added to calculate each inter-gauge correlation coefficient. The final number of rainfall data sets was selected using the correlation coefficient from a pair of rain gauges at the maximum distance to provide a threshold value. The term 'steady state' means that the fluctuation of correlation coefficients is small as more rainfall data are added. The inter-gauge correlation coefficients under the threshold value were discarded for generating averaged CCs. Therefore, the averaged CC for each distance is the mean of the steady-state correlation coefficients above the threshold. These averaged CCs represent similarities in properties between the rain gauges. After generating the averaged CCs, a spatial correlation-coefficient diagram consisting of the relations between the averaged CCs and the 
distances at each rain gauge was generated. Plotting a spatial correlation coefficient diagram is a prior procedure to estimating the representative correlation distances for the correlogram model using a parametric model fitting process. For this fitting process, the modified-exponential model (Ciach and Krajewski 2006) without the nugget effect $\left(c_{0}=1\right)$ was selected to generate the correlation distance $\left(d_{0}\right)$, which is a representative value for each rain gauge.

$\rho_{\text {ave }}(X Y)=\frac{\sum_{n=T R}^{T N_{X Y}} \rho_{X Y, n}}{\left(T N_{X Y}-T R\right)}$

$\rho(d)=c_{0} \exp \left(-\frac{d}{d_{0}}\right)^{S_{0}}$

Where,

$\rho_{\text {ave }}(X Y)$ : average inter-gauge correlation coefficient at various distances $(X$ : indicator of a specified rain-gauge location, $Y$ : indicator of other rain-gauge locations);

$\rho(d)$ : correlation function with distance between two rain gauges;

$n$ : number of rainfall data;

$T N_{X Y}$ : total number of rainfall data;

$T R$ : threshold (for this study, $T R=20$ );

$d$ : distance between two rain gauges; $c_{0}$ : correlation for near-zero points (nugget);

$d_{0}$ : correlation distance;

$S_{0}$ : shape parameter dependent on time-scale $\left(0 \mathrm{hr}: S_{0}=1\right.$; $\left.1 \mathrm{hr}: S_{0}=1.57\right)$.

From the representative correlation distance $\left(d_{0}\right)$, the radius of the effective area $(r)$ can be generated based on the Nyquist theory using the assumption of a spatially homogenous and isotropic rainfall condition (Yoo et al. 2003). Consequently, each rain gauge has its own effective radius with respect to the rainfall intensity.

$r=\left[\frac{\left(d_{0} / 2\right)^{2}}{\pi}\right]^{0.5}$

\section{RESULTS AND DISCUSSION}

\subsection{Spatial Correlation Coefficient Diagram}

For each rain gauge in Nam River Basin, there are 23 inter-gauge correlation coefficients. As an example, Fig. 3 presents the inter-gauge correlation coefficients between the Macheon rain gauge and the other 23 rain gauges along with their distance information. The total number of rainfall data for each distance varies due to the requirement of case A $(X>0$ and $Y>0)$. There are 151 and 208 rainfall data sets for rain-gauge distances of 38.3 and $11.4 \mathrm{~km}$, respectively. The nearest rain gauges have more occurrences of case $\mathrm{A}$

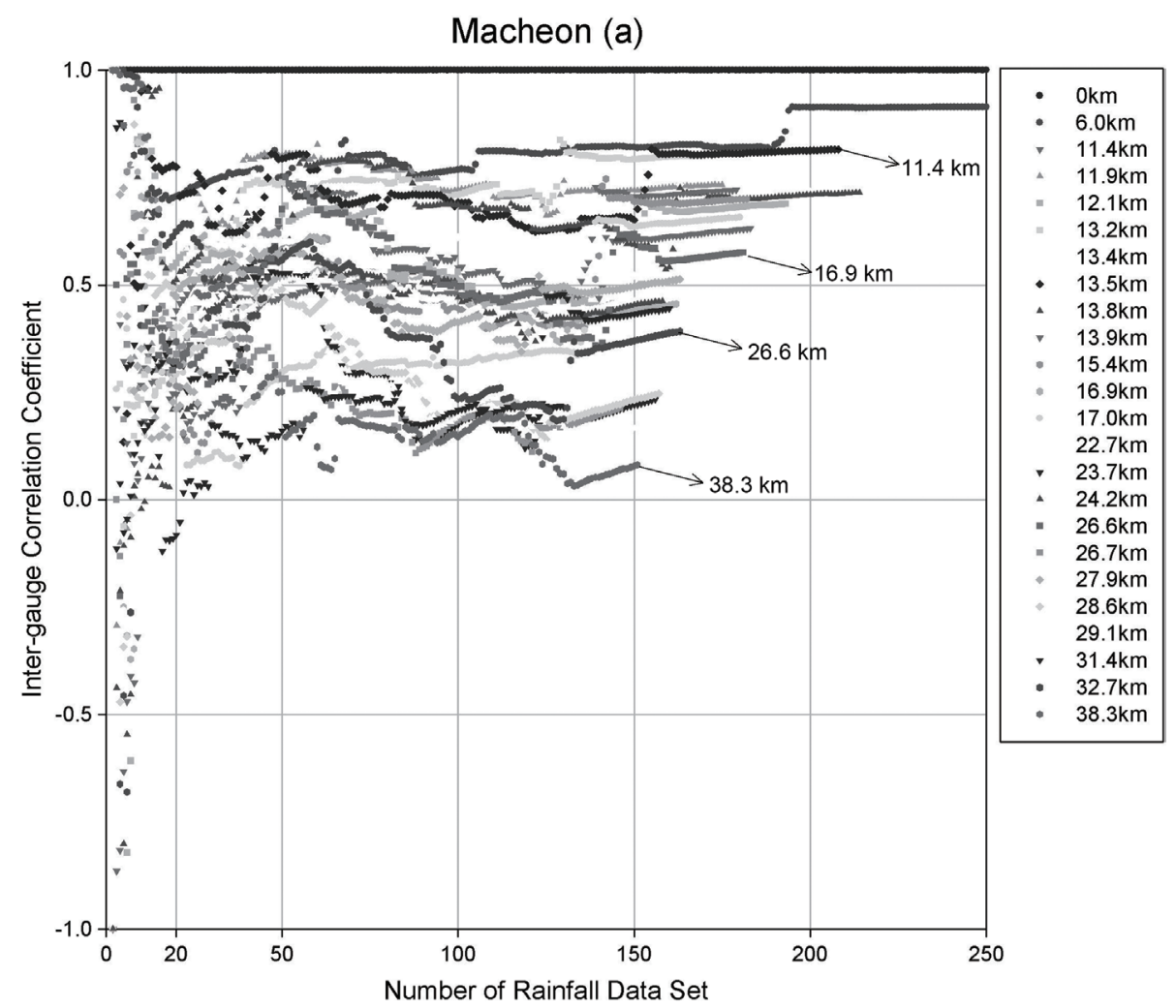

Fig. 3. Correlation coefficients at various distances from the Macheon rain gauge with a threshold (number of rainfall data set: 20) application. 
and a higher correlation coefficient with smaller variations. From Fig. 3, the approximate steady states of the inter-gauge correlation coefficients start when 20 rainfall data sets are included. The averaged CCs at each distance were generated from an average of the inter-gauge correlation coefficients after 20 rainfall data sets (threshold) were excluded. To present the improvement of representation of effective radius for each rain gauge based on the inter-gauge correlation coefficients, the averaged CCs were compared with the last CCs. Obtained averages of correlation coefficients for each rain-gauge distance were plotted on the spatial correlationcoefficient diagram, which provides the relations between the averaged CCs and the rain-gauge distance (Fig. 4). A representative correlation distance $\left(d_{0}\right)$ for each rain gauge was generated from the fitting process using the modified exponential model as a correlogram (Ciach and Krajewski 2006). For the fitting process, the sum of squared differences between the inter-gauge correlation coefficient and the modified exponential model were minimized. The Nam River Basin has similar spatial correlation patterns to the study cases of Guam, Florida, and Oklahoma investigated by Krajewski et al. (2003). For our study, given the limitations of rain-gauge installations, we did not consider random measurement errors of the rain gauges, which can display micro-scale variability (Habib et al. 2001). The finalized correlation functions based on the modified exponential model for 24 rain gauges are presented in Table 1 with the finalized correlation distances. These correlation distances are related to the terrain information of the Nam River Basin, because mountainous terrain interacting with atmospheric phenomena can increase the variability of precipitation patterns, which is the main factor affecting inter-gauge correlation.

Figure 5a shows the determination coefficients $\left(R^{2}\right)$ when the average or last CCs were applied to generate the representative correlation distance of each rain gauge in the spatial correlation-coefficient fitting process. Compared with use of the last CC, the averaged CCs provide the better determination coefficient except for rain gauges $\mathrm{A}$ and $\mathrm{K}$, which are classified as higher altitude. The last CCs showed larger fluctuations in the determination coefficient for these 2 stations ( 0.6$)$. The averaged CCs can provide a robust way to present the correlation distance for all rainfall events at each location with minimum fluctuations in terms of the determination coefficient. In generating the correlation distances for this study, the shape parameter and nugget effects in Eq. (3) were not considered (i.e., $S_{0}=1$ and $c_{0}=1$, respectively). Following the research by Ciach and Krajewski (2006), the shape parameter should be 1.57, since 1 hour was the temporal scale of rainfall accumulation for the rainfall data set. However, without shape parameters, the determination coefficient was better for all rain gauge locations in the spatial correlation-coefficient fitting process for each rain gauge (Fig. 5b). When the shape parameter was considered, most rain gauge locations $(\mathrm{A}-\mathrm{G}$ and $\mathrm{K})$ in the higher altitude class generated determination coefficients of less than 0.5 with smaller fluctuations in their determination coefficients. In contrast, lower altitude rain gauges yielded better determination coefficients, except for three rain gauges ( $\mathrm{f}-\mathrm{h}<0.5$ ), but with larger fluctuations $(\sim 0.4)$. The maximum difference in the determination coefficients was approximately 0.4 in the shape parameter comparison. The size of the compared rain-gauge distance could be the reason for this discrepancy. Ciach and Krajewski (2006) reported that the shape parameter controlled the functional performance in Eq. (3) for small separation distances.

The radius of the effective area for each rain gauge was calculated and plotted in Fig. 6 using Eq. (3). Figure 6a presents the effective radii generated from the correlation

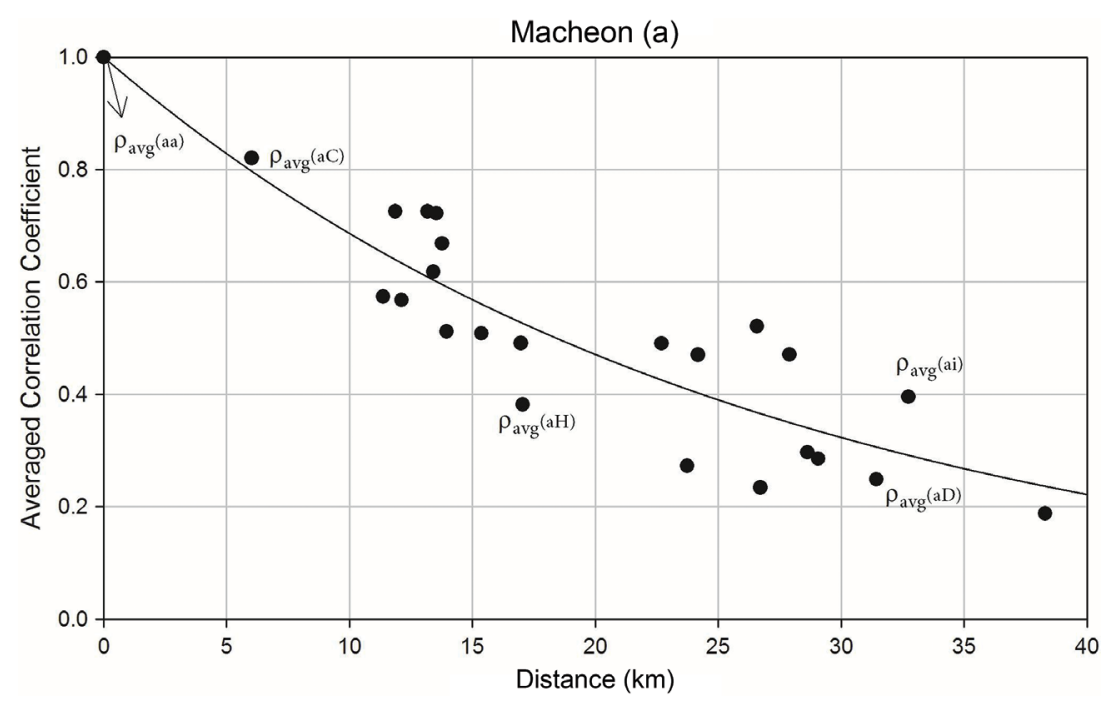

Fig. 4. Spatial diagram of the fitting procedure at the Macheon rain gauge with high correlation of determination $(0.80)$. The line represents the correlation function with data points indicating the average inter-gauge correlation coefficients at various distances. 
Table 1. Generated correlation functions and distances with respect to the average inter-gauge correlation coefficients for various distances.

\begin{tabular}{|c|c|c|}
\hline Rain Gauge Name (Index, EL. m) & Correlation Function & Correlation Distance $(\mathbf{k m})$ \\
\hline Sanne $(A, 860)$ & $\rho=\exp (-0.0276 \times d)$ & 36.21 \\
\hline Samjang $(B, 640)$ & $\rho=\exp (-0.0334 \times d)$ & 29.92 \\
\hline Samjeong $(\mathrm{C}, 600)$ & $\rho=\exp (-0.0316 \times d)$ & 31.69 \\
\hline Seosang $(D, 450)$ & $\rho=\exp (-0.0424 \times d)$ & 23.57 \\
\hline Seoha $(E, 360)$ & $\rho=\exp (-0.0302 \times d)$ & 33.07 \\
\hline Sicheon $(F, 660)$ & $\rho=\exp (-0.0326 \times d)$ & 38.68 \\
\hline Ayong $(\mathrm{G}, 480)$ & $\rho=\exp (-0.0352 \times d)$ & 28.45 \\
\hline Unbong1 $(\mathrm{H}, 500)$ & $\rho=\exp (-0.0507 \times d)$ & 19.74 \\
\hline Unbong2 (I, 460) & $\rho=\exp (-0.0383 \times d)$ & 26.09 \\
\hline Jungsan $(\mathrm{J}, 40)$ & $\rho=\exp (-0.0350 \times d)$ & 28.54 \\
\hline Chawhang $1(\mathrm{~K}, 360)$ & $\rho=\exp (-0.0296 \times d)$ & 33.76 \\
\hline Chawhang2 (L, 340) & $\rho=\exp (-0.0307 \times d)$ & 32.58 \\
\hline Macheon $(\mathrm{a}, 260)$ & $\rho=\exp (-0.0376 \times d)$ & 26.57 \\
\hline Sancheong (b, 130) & $\rho=\exp (-0.0422 \times d)$ & 23.71 \\
\hline Samga $(c, 80)$ & $\rho=\exp (-0.0338 \times d)$ & 29.58 \\
\hline Sukok $(\mathrm{d}, 120)$ & $\rho=\exp (-0.0425 \times d)$ & 23.53 \\
\hline Sinan $(e, 55)$ & $\rho=\exp (-0.0347 \times d)$ & 28.84 \\
\hline Aneui (f, 200) & $\rho=\exp (-0.0338 \times d)$ & 29.56 \\
\hline Imcheon $(\mathrm{g}, 135)$ & $\rho=\exp (-0.0397 \times d)$ & 25.91 \\
\hline Jilisan $(\mathrm{h}, 340)$ & $\rho=\exp (-0.0324 \times d)$ & 30.91 \\
\hline Changchon $(I, 60)$ & $\rho=\exp (-0.0253 \times d)$ & 39.47 \\
\hline Cheongam $(\mathrm{j}, 260)$ & $\rho=\exp (-0.0457 \times d)$ & 21.87 \\
\hline Tesu $(\mathrm{k}, 85)$ & $\rho=\exp (-0.0431 \times d)$ & 23.23 \\
\hline Hamyang (I, 180) & $\rho=\exp (-0.0343 \times d)$ & 29.15 \\
\hline
\end{tabular}
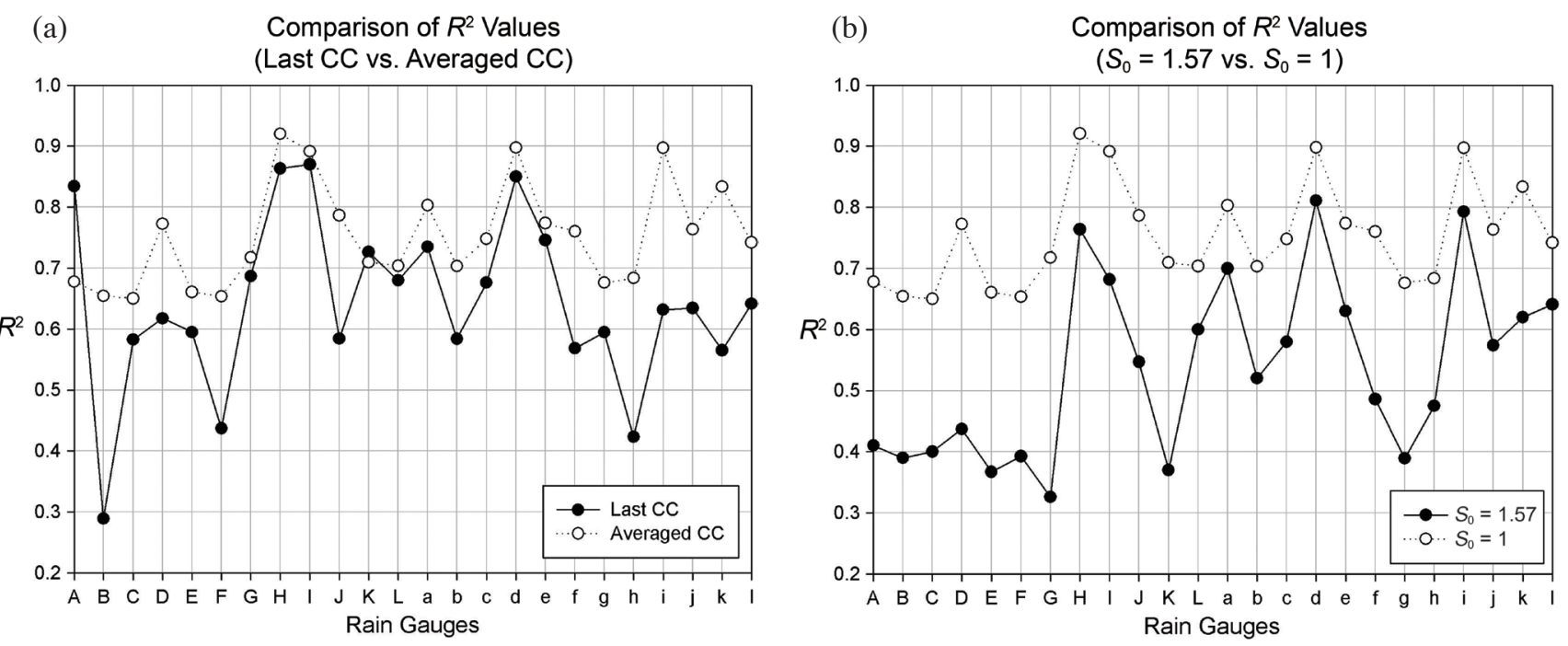

Fig. 5. Comparisons of R-square values for diverse conditions using the correlation coefficient (a) and the correlation fitting model (b). 

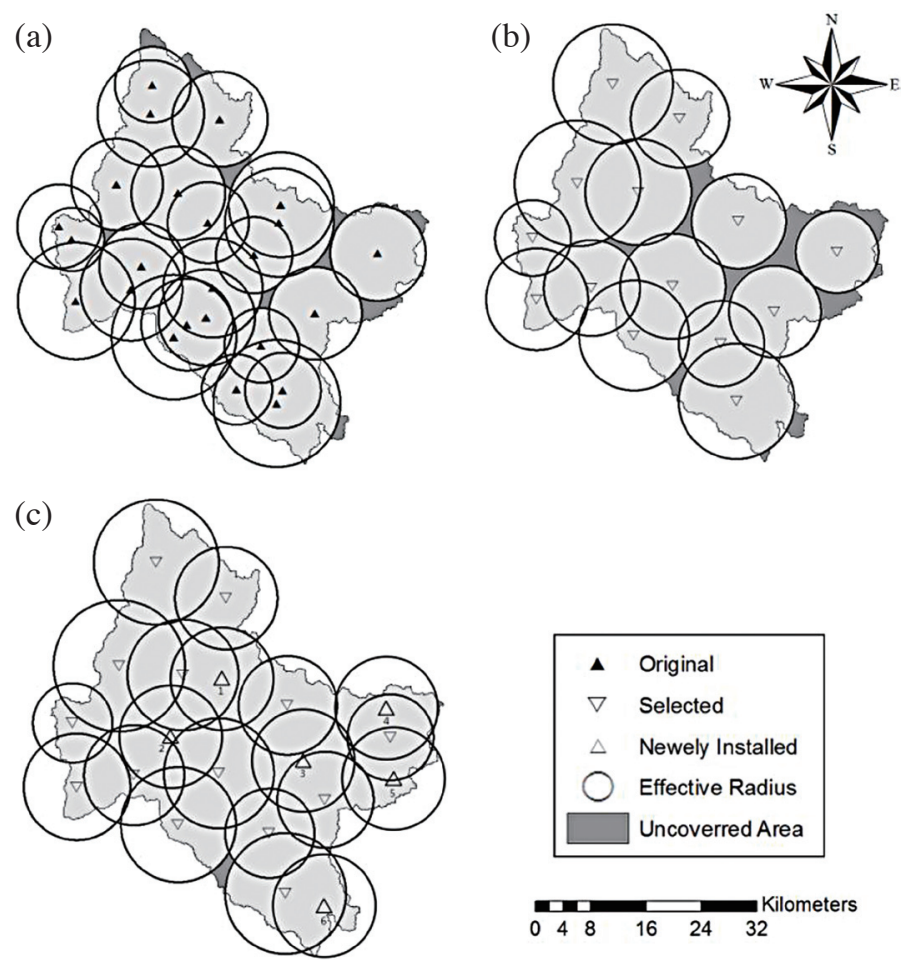

Fig. 6. Effective radii for current rain gauges based on the average inter-gauge correlation coefficient (a), minimized redundancy with rain-gauge selection (b), and optimized rain-gauge distribution with newly installed rain gauges (c).

distances for the current rain-gauge distribution, displaying both overlapping and/or missed (dark shaded) effective areas. For some missed areas in Fig. 6a, additional rain gauges are necessary to cover the entire area. On the other hand, overlapping areas shown in the southwest part of the map in Fig. 6a should be rearranged to optimize the rainfall estimation. Effective radii with minimum overlapped areas, generated by selecting optimal rain gauges are presented in Fig. 6b. Effective radii in Fig. 6b were regenerated with decreased or increased size after selection. Figure $6 \mathrm{c}$ shows the six additional rain gauges needed to cover the entire area based on the effective radii. These additional rain gauges were added discretionally where the coverage of effective radius is required. For the selection of locations for additional rain gauges for the future studies, an optimization function based on the effective radius with minimum overlapped areas should be applied. Because the effective radii were regenerated in Fig. 6b, after all additional rain gauges were added, the effective radii were obtained by using following procedure. [(1) Regenerate average inter-gauge correlation coefficients; (2) plot spatial correlation coefficient diagrams; (3) obtain correlation distances using the correlogram model; (4) recalculate the radius of the effective area for each rain gauge]. The new optimized distribution of rain gauges is presented in Fig. 6c. To validate the robustness of the averaged CC functions, the effective radius for 8 years (2003 - 2010) was plotted in Fig. 7. For the Macheon rain gauge, the size of the effective radius increased from $\sim 7.5$ to $\sim 12.5 \mathrm{~km}$ when averaged CC functions were employed. The final correlation coefficient showed unusual changes in the effective radius in 2006, which could be because of the limited number of rainfall data sets. If the number of rainfall data sets increased without limitation, the correlation coefficient would be augmented continuously. Therefore, the specified rainfall duration (chosen as 250 hours for this study) to estimate the correlation distance may considerably influence the results. Furthermore, the standard deviations of the effective radius sizes for 8 years at all rain gauges were obtained for both methods (Fig. 8). The robustness of the averaged CC calculation was clearly supported by a lower standard deviation of the effective radius at each rain gauge than the results obtained from using the last-value CCs. Rain gauge $\mathrm{d}$ had the lowest standard deviation difference, though other locations had at least $\sim 3 \mathrm{~km}$ difference. In addition, the fluctuations in the standard deviations for all rain gauges were between $\sim 2$ and $\sim 3.2 \mathrm{~km}$ using the averaged CCs.

\subsection{Altitude Effects on Radius of Effective Area}

The impacts of altitude on the effective radius at each rain gauge are substantial because most parts of the Korean Peninsula are mountainous. The requirements for rain-gauge installation are based on diverse properties of the environment at the potential locations. Previous research found that rainfall patterns depend on mountain characteristics (Carruthers and Choularton 1983) such as slope, which can develop 
regional clouds containing plenty of rainfall (Barros and $\mathrm{Ku}-$ ligowski 1998). As such, the World Meteorological Organization (WMO 1994) suggested minimum numbers of rain gauges for a region based on the location type. Plains should have one rain gauge per $600-900 \mathrm{~km}^{2}$ while mountainous areas should have one rain gauge per $100-250 \mathrm{~km}^{2}$. The study area, the Nam River Basin, has 24 rain gauges with altitudes between 55 and $860 \mathrm{~m}$. To study the effects of altitude on the radius of effective area, the data were divided into two class- es (twelve higher and twelve lower than the median altitude of $360 \mathrm{~m}$ of the rain gauges). In each category, the average distances for each rain gauge to the others were measured. The measured average distances were compared between the higher and lower altitude classes to select a pair with comparable average distances (Tables 2 and 3 ). This pair was compared in terms of the radius of effective area to see the effect of altitude. Based on this controlled condition, the altitudes of rain gauges could be a major contributor of the magnitude

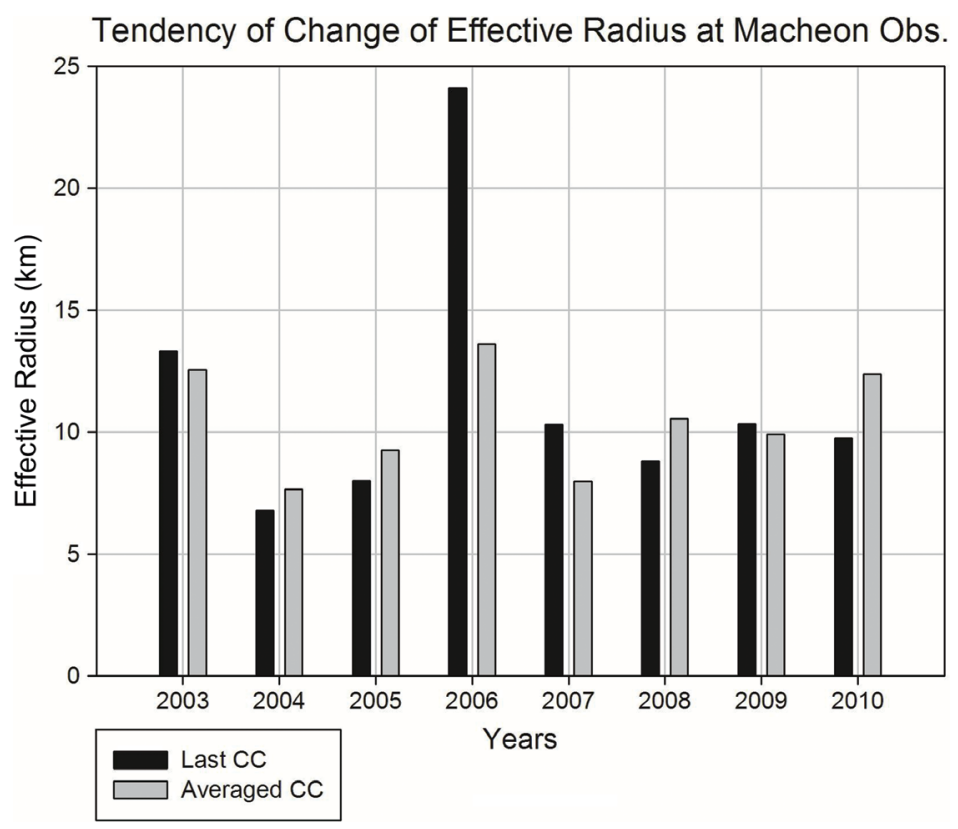

Fig. 7. Effective radius at Macheon rain gauge for 8 years.

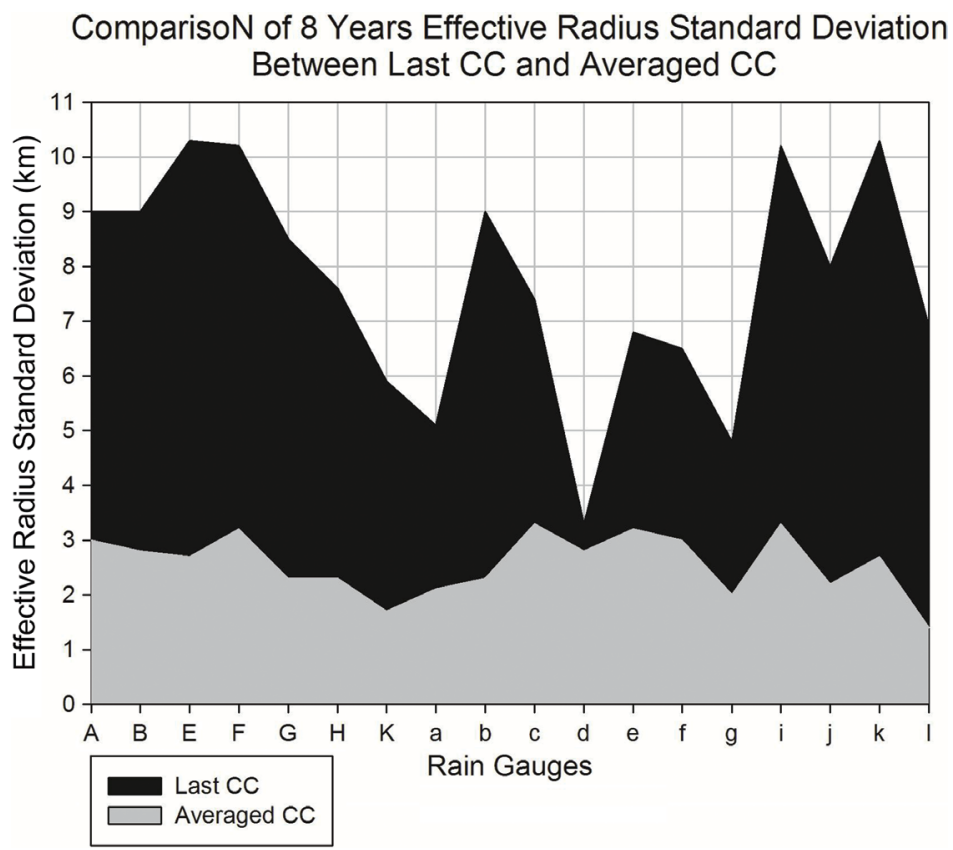

Fig. 8. Comparisons of standard deviations for 8 years effective radius at each rain gauge. 
Table 2. Pairs of the comparison from higher to lower rain gauges (all indices include mean distance in $\mathrm{km}$ ).

\begin{tabular}{cccc}
\hline Number & Higher Rain Gauge Index & Compared Lower Rain Gauge Index & Mean Distance Difference (km) \\
\hline 1 & A (21.71) & $\mathrm{a}(21.70)$ & 0.01 \\
2 & $\mathrm{~B}(21.11)$ & $\mathrm{a}(21.70)$ & 0.59 \\
3 & $\mathrm{C}(18.35)$ & $\mathrm{g}(19.06)$ & 0.71 \\
4 & $\mathrm{D}(29.29)$ & $\mathrm{f}(31.43)$ & 2.14 \\
5 & $\mathrm{E}(26.27)$ & $\mathrm{c}(26.83)$ & 0.56 \\
6 & $\mathrm{~F}(21.78)$ & $\mathrm{j}(21.82)$ & 0.04 \\
7 & $\mathrm{G}(20.08)$ & $\mathrm{d}(19.82)$ & 0.53 \\
8 & $\mathrm{H}(21.95)$ & $\mathrm{j}(21.82)$ & 0.13 \\
9 & $\mathrm{I}(20.37)$ & $\mathrm{d}(19.55)$ & 0.82 \\
10 & $\mathrm{~J}(20.42)$ & $\mathrm{d}(19.55)$ & 0.87 \\
11 & $\mathrm{~K}(25.74)$ & $\mathrm{c}(26.83)$ & 1.09 \\
12 & $\mathrm{~L}(25.05)$ & $\mathrm{i}(23.60)$ & 1.45 \\
\hline
\end{tabular}

Table 3. Pairs of the comparisons from lower to higher rain gauges (all indices include mean distance in $\mathrm{km}$ ).

\begin{tabular}{cccc}
\hline Number & Lower Rain Gauge Index & Compared Higher Rain Gauge Index & Mean Distance Difference (km) \\
\hline 1 & $\mathrm{a}(21.70)$ & $\mathrm{A}(21.70)$ & 0.01 \\
13 & $\mathrm{~b}(16.88)$ & $\mathrm{C}(18.35)$ & 1.47 \\
5 & $\mathrm{c}(26.83)$ & $\mathrm{E}(26.27)$ & 0.56 \\
7 & $\mathrm{~d}(19.55)$ & $\mathrm{G}(20.08)$ & 0.53 \\
14 & $\mathrm{e}(19.15)$ & $\mathrm{C}(18.35)$ & 0.80 \\
4 & $\mathrm{f}(31.43)$ & $\mathrm{D}(29.29)$ & 2.14 \\
3 & $\mathrm{~g}(19.06)$ & $\mathrm{C}(18.35)$ & 0.71 \\
15 & $\mathrm{~h}(16.64)$ & $\mathrm{C}(18.35)$ & 1.71 \\
12 & $\mathrm{i}(23.60)$ & $\mathrm{L}(25.05)$ & 1.45 \\
6 & $\mathrm{j}(21.82)$ & $\mathrm{F}(21.78)$ & 0.04 \\
16 & $\mathrm{k}(17.48)$ & $\mathrm{C}(18.35)$ & 0.87 \\
17 & $\mathrm{l}(23.41)$ & $\mathrm{H}(21.95)$ & 1.46 \\
\hline
\end{tabular}

of the effective radius of the selected pair. Figure 9 compares the effective radii between lower and higher rain-gauge locations. In this analysis, the higher altitude rain gauges generally had larger effective radii except for three pairs $(4,8$, and 17). Pair 6 has the largest difference in effective radius of around $4.6 \mathrm{~km}$. The largest effective radius can be found at rain gauge $\mathrm{F}$ at the higher altitude location. The reason for the lower altitude having a lower effective radius in the Nam River Basin might be due to the terrain shape. In particular, some lower altitude rain gauges are surrounded by mountains, which can reduce the correlation between other rain gauges at lower elevations. In addition, Lim and Lee (1994) found that higher altitude areas in a mountainous region can have more rainfall because of orographic effects producing cumulative cloud clusters with substantial amounts of rainfall. A larger amount of rainfall can cause higher correlation coefficients and larger effective radii (Fig. 7).

\section{SUMMARY AND CONCLUSIONS}

To minimize flood damage in mountainous areas, accurate rainfall measurements are required. For better rainfall measurements, a new method (i.e., averaged CC) was developed to evaluate rain gauge distributions when both rain gauges satisfy Case $\mathrm{A}(X>0$ and $Y>0)$. Rain gauge distributions generated by averaged $\mathrm{CC}$ were compared 


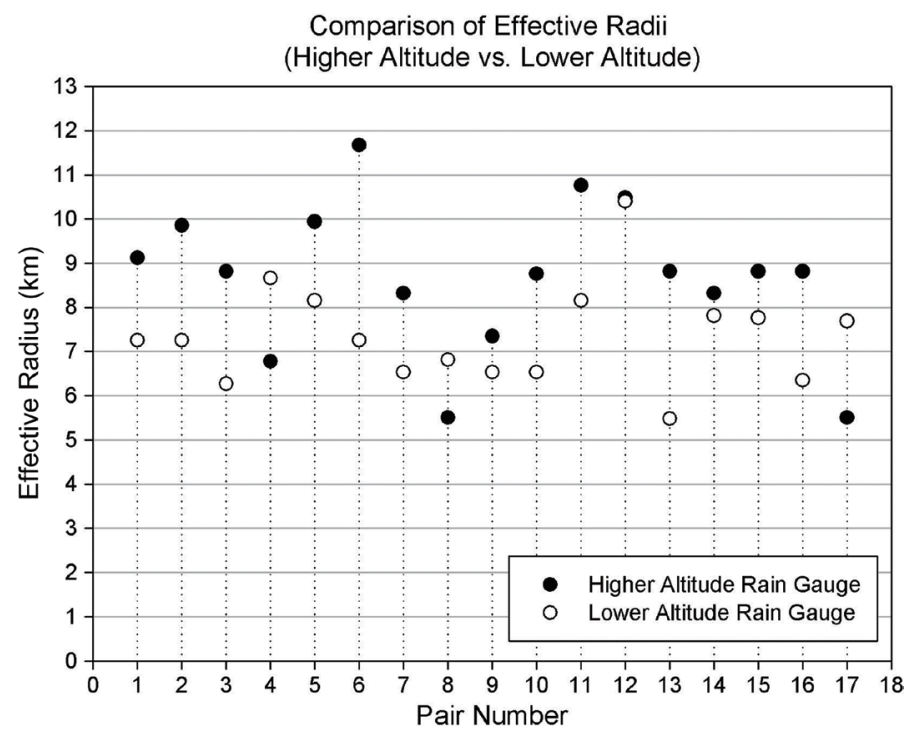

Fig. 9. Influences of altitude on the effective radii (pair numbers are in Table 2).

with those produced using the last $\mathrm{CC}$. The procedure to find the effective radius of each rain gauge using averaged $\mathrm{CC}$ was as follows: first, the inter-gauge correlation coefficient between each pair of rain gauges was calculated while increasing of number of rainfall data sets by expanding the time range. From the inter-gauge correlation coefficient, averaged CCs were obtained after adopting a threshold. The generated averaged CCs were plotted in a spatial correlation-coefficient diagram with distance information. An estimate of the correlation distance at each rain gauge was then obtained. Based on the correlation distances for every rain gauge, the effective radii were produced and plotted to show the effectiveness of the rain-gauge distribution. The method was evaluated on the Nam River Basin located in the southern part of South Korea using hourly rainfall data. In the procedure for calculating correlation distances, the new method provided a lower coefficient of determination compared to when the last $\mathrm{CC}$ and shape parameters were applied. A threshold number of rainfall data sets must be used to calculate the averaged CCs because near steady-state correlation coefficients are required to define the characteristics of rain gauges. For this study, the threshold was the first 20 rainfall data sets following highly fluctuating correlation coefficients. In comparing performances for eight years (2003 - 2010), the averaged CCs had a lower standard deviation for every rain gauge than when last CCs were used. Based on the effective radii using averaged CCs, the Nam River Basin requires six new rain gauges to adequately cover the whole area. Rain gauges at higher elevations show larger effective radii than those at lower elevations.

Acknowledgements This research was supported by a grant (NEMA-NH-2011-45) from the Natural Hazard Mitigation Research Group, National Emergency Management Agency of Korea. The authors wish to thank the WAter Management Information System(WAMIS) in Korea for providing site characteristics and meteorological data.

\section{REFERENCES}

Adler, R. F., C. Kidd, G. Petty, M. Morissey, and H. M. Goodman, 2001: Intercomparison of global precipitation products: The third Precipitation Intercomparison Project (PIP-3). Bull. Amer. Meteorol. Soc., 82, 13771396, doi: 10.1175/1520-0477(2001)082<1377:IOGP PT>2.3.CO;2. [Link]

Al-Zahrani, M. and T. Husain, 1998: An algorithm for designing a precipitation network in the south-western region of Saudi Arabia. J. Hydrol., 205, 205-216, doi: 10.1016/S0022-1694(97)00153-4. [Link]

Arnaud, P., J. Lavabre, C. Fouchier, S. Diss, and P. Javelle, 2011: Sensitivity of hydrological models to uncertainty in rainfall input. Hydrolog. Sci. J., 56, 397-410, doi: 10.1080/02626667.2011.563742. [Link]

Barca, E., G. Passarella, and V. Uricchio, 2008: Optimal extension of the rain gauge monitoring network of the Apulian Regional Consortium for Crop Protection. Environ. Monit. Assess., 145, 375-386, doi: 10.1007/ s10661-007-0046-z. [Link]

Barros, A. P. and R. J. Kuligowski, 1998: Orographic effects during a severe wintertime rainstorm in the Appalachian mountains. Mon. Weather Rev., 126, 2648-2672, doi: 10.1175/1520-0493(1998)126<2648:OEDASW>2 . 0.CO;2. [Link]

Bastin, G., B. Lorent, C. Duqué, and M. Gevers, 1984: Optimal estimation of the average areal rainfall and optimal selection of rain gauge locations. Water Resour. Res., 20, 463-470, doi: 10.1029/WR020i004p00463. [Link] 
Berndtsson, R. and J. Niemczynowicz, 1988: Spatial and temporal scales in rainfall analysis - some aspects and future perspective. J. Hydrol., 100, 293-313, doi: 10.1016/0022-1694(88)90189-8. [Link]

Berne, A., G. Delrieu, J. D. Creutin, and C. Obled, 2004: Temporal and spatial resolution of rainfall measurements required for urban hydrology. J. Hydrol., 299, 166-179, doi: 10.1016/j.jhydrol.2004.08.002. [Link]

Burn, D. H. and I. C. Goulter, 1991: An approach to the rationalization of streamflow data collection networks. J. Hydrol., 122, 71-91, doi: 10.1016/0022-1694(91)90173-F. [Link]

Carruthers, D. J. and T. W. Choularton, 1983: A model of the feeder-seeder mechanism of orographic rain including stratification and wind-drift effects. Q.J.R.Meteorol. Soc., 109, 575-588, doi: 10.1002/qj.49710946109. [Link]

Ciach, G. J. and W.F. Krajewski, 2006: Analysis and modeling of spatial correlation structure in small-scale rainfall in Central Oklahoma. Adv. Water Resour., 29, 14501463, doi: 10.1016/j.advwatres.2005.11.003. [Link]

Chebbi, A., Z. K. Bargaoui, and M. da C. Cunha, 2011: Optimal extension of rain gauge monitoring network for rainfall intensity and erosivity index interpolation. J. Hydrol. Eng., 16, 665-676, doi: 10.1061/(ASCE) HE.1943-5584.0000353. [Link]

Chen, Y. C., C. Wei, and H. C. Yeh, 2008: Rainfall network design using kriging and entropy. Hydrol. Process., 22, 340-346, doi: 10.1002/hyp.6292. [Link]

Cheng, K. S., Y. C. Lin, and J. J. Liou, 2008: Rain-gauge network evaluation and augmentation using geostatistics. Hydrol. Process., 22, 2554-2564, doi: 10.1002/ hyp.6851. [Link]

Frei, C. and C. Schär, 1998: A precipitation climatology of the Alps from high-resolution rain-gauge observations. Int. J.Climatol., 18, 873-900, doi: 10.1002/(SICI)10970088(19980630)18:8<873::AID-JOC255>3.0.CO;2-9. [Link]

Ha, E. and C. Yoo, 2007: Use of mixed bivariate distributions for deriving inter-station correlation coefficients of rain rate. Hydrol. Process., 21, 3078-3086, doi: 10.1002/hyp.6526. [Link]

Habib, E., W. F. Krajewski, and A. Kruger, 2001: Sampling errors of tipping-bucket rain gauge measurements. $J$. Hydrol. Eng., 6, 159-166, doi: 10.1061/(ASCE)10840699(2001)6:2(159). [Link]

Johnson, D., M. Smith, V. Koren, and B. Finnerty, 1999: Comparing mean areal precipitation estimates from NEXRAD and rain gauge networks. J. Hydrol. Eng., 4, 117-124, doi: 10.1061/(ASCE)1084-0699(1999)4:2(117). [Link]

Kassim, A. H. M. and N. T. Kottegoda, 1991: Rainfall network design through comparative kriging methods. Hydrolog. Sci. J., 36, 223-240, doi: 10.1080/ 02626669109492505. [Link]
Krajewski, W. F., 1987: Cokriging radar-rainfall and rain gage data. J. Geophys. Res., 92, 9571-9580, doi: 10.1029/JD092iD08p09571. [Link]

Krajewski, W. F. and K. P. Georgakakos, 1994: Hydrologi$\mathrm{cal}$ and meteorological aspects of rainfall measurement and predictability. J. Appl. Meteorol., 33, 1381-1660.

Krajewski, W. F., G. J. Ciach, and E. Habib, 2003: An analysis of small-scale rainfall variability in different climatic regimes. Hydrolog. Sci. J., 48, 151-162, doi: 10.1623/hysj.48.2.151.44694. [Link]

Lim, E. H. and T. Y. Lee, 1994: Two-dimensional numerical study of the terrain effects on the development of cloud and precipitation for the middle part of Korea. Asia Pac. J. Atmos. Sci., 30, 565-582. (in Korean)

McCollum, J. R., W. F. Krajewski, R. R. Ferraro, and M. B. $\mathrm{Ba}, 2002$ : Evaluation of biases of satellite rainfall estimation algorithms over the continental United States. J. Appl. Meteorol., 41, 1065-1080, doi: 10.1175/15200450(2002)041<1065:EOBOSR>2.0.CO;2. [Link]

Morin, J., D. Rosenfeld, and E. Amitai, 1995: Radar rain field evaluation and possible use of its high temporal and spatial resolution for hydrological purposes. J. Hydrol., 172, 275-292, doi: 10.1016/0022-1694(95)02700-Y. [Link]

North, G. R., S. S. P. Shen, and R. B. Upson, 1991: Combining rain gages with satellite measurements for optimal estimates of area-time averaged rain rates. Water Resour. Res., 27, 2785-2790, doi: 10.1029/91WR01744. [Link]

Pardo-Igúzquiza, E., 1998: Optimal selection of number and location of rainfall gauges for areal rainfall estimation using geostatistics and simulated annealing. J. Hydrol., 210, 206-220, doi: 10.1016/S0022-1694(98)00188-7. [Link]

Piman, T. and M. S. Babel, 2013: Prediction of rainfall-runoff in an ungauged basin: Case study in the mountainous region of northern Thailand. J. Hydrol. Eng., 18, 285-296, doi: 10.1061/(ASCE)HE.1943-5584.0000573. [Link]

Tsintikidis, D., K. P. Georgakakos, J. A. Sperfslage, D. E. Smith, and T. M. Carpenter, 2002: Precipitation uncertainty and raingauge network design within Folsom lake watershed. J. Hydrol. Eng., 7, 175-184, doi: 10.1061/(ASCE) 1084-0699(2002)7:2(175). [Link]

Wheater, H. S., V. S. Isham, C. Onof, R. E. Chandler, P. J. Northrop, P. Guiblin, S. M. Bate, D. Cox, and D. Koutsoyiannis, 2000: Generation of Spatially Consistent Rainfall Data, Report to the Ministry of Agriculture, Fisheries and Food, Tech. Rep. 204, Department of Civil and Environmental Engineering, Imperial College of Science, Technology and Medicine, and Department of Statistical Science, University College London, London.

WMO (World Meteorological Organization), 1994: Guide to Hydrological Practices, WOM-164, Geneva. 
Xie, P., A. Yatagai, M. Chen, T. Hayasaka, Y. Fukushima, C. Liu, and S. Yang, 2007: A gauge-based analysis of daily precipitation over East Asia. J. Hydrometeorol., 8, 607-626, doi: 10.1175/JHM583.1. [Link]

Yoo, C. and E. Ha, 2007: Effect of zero measurements on the spatial correlation structure of rainfall. Stoch. Environ. Res. Risk Assess., 21, 287-297, doi: 10.1007/ s00477-006-0064-3. [Link]

Yoo, C., I. Kim, and S. Ryoo, 2003: Evaluation of raingauge density and spatial distribution: A case study for Nam Han River Basin. J. Korea Water Resour. As., 36, 173181, doi: 10.3741/JKWRA.2003.36.2.173. (in Korean) [Link]

Younger, P. M., J. E. Freer, and K. J. Beven, 2009: Detecting the effects of spatial variability of rainfall on hydrological modelling within an uncertainty analysis framework. Hydrol. Process., 23, 1988-2003, doi: 10.1002/hyp.7341. [Link] 